\title{
Vascular cell adhesion molecule-1 in rheumatoid arthritis patients
}

\author{
Relation to disease activity, oxidative stress, and systemic inflammation
}

Heba R. Salem, MD, Enas S. Zahran, MD.

\begin{abstract}
الأهداف : تقييم دور جزيء التصاق الخلايا الوعائية- ا في الخلل الوظيفي للخلايا

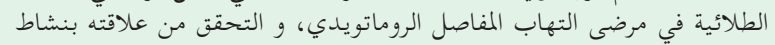

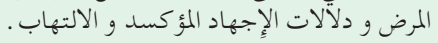

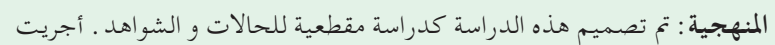

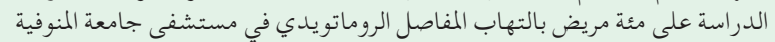

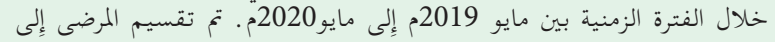

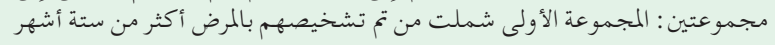

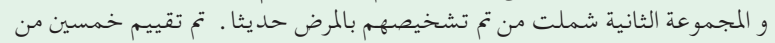

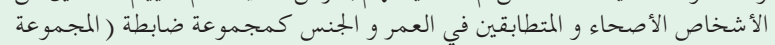

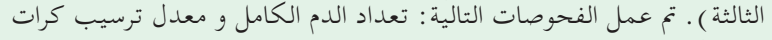

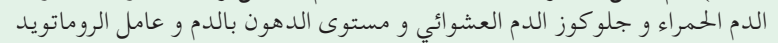

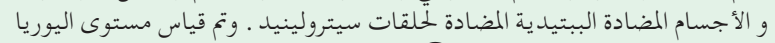

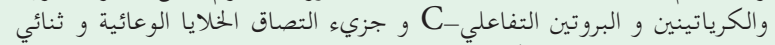

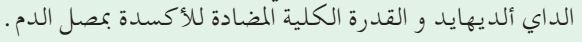

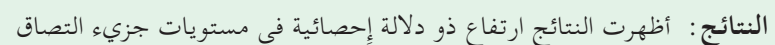

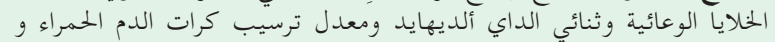

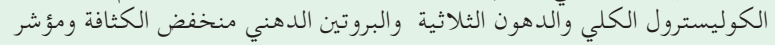

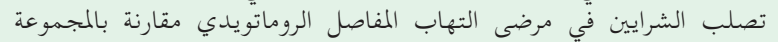

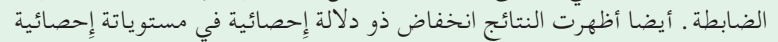

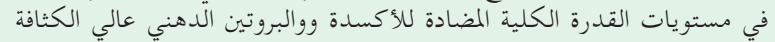

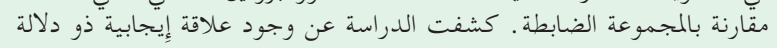

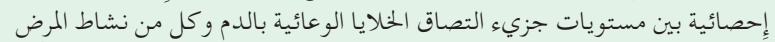

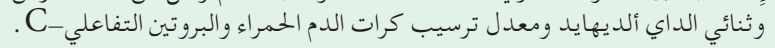

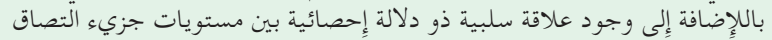

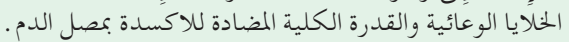

الخلاصة : كشفت الدراسة عن وجود ارتفاع مستويات جزيء الرواء التصاق الخلايا

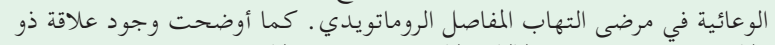

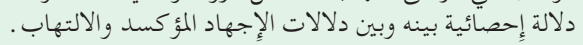

Objectives: To evaluate the potential role of vascular cell adhesion molecule-1 (VCAM-1), an endothelial factor, in endothelial dysfunction in rheumatoid arthritis (RA) patients, and to determine its relation to disease activity, oxidative stress, and inflammatory markers.

Methods: This study was designed as a cross-sectional casecontrol study. One-hundred patientswith RAwereselected from out-patient clinics of Menoufia University Hospital, Menoufia, Egypt from May 2019 to May 2020. Fifty patients previously diagnosed with RA for more than 6 months were included as Group I, and fifty patients newly diagnosed with RA were included as Group II. Fifty healthy age- and gender-matched individuals were evaluated as the control group (Group III). Complete blood count, random blood glucose, erythrocyte sedimentation rate (ESR), lipid profile, rheumatoid factor, anti-cyclic citrullinated peptide antibodies, serum levels of urea, creatinine, C-reactive protein, VCAM-1, malondialdehyde, and total antioxidant capacity were determined.

Results: Patients with RA showed significantly higher serum VCAM-1, malondialdehyde, ESR, C-reactive protein, triglycerides, total cholesterol, low-density lipoprotein, and atherogenic index levels than the control group. Also, they showed significantly lower total antioxidant capacity and high-density lipoprotein levels than control group. A significant positive correlation between serum VCAM-1 with disease activity, serum malondialdehyde, ESR, and C-reactive protein was observed. Also, a significant negative correlation between serum VCAM-1 and total antioxidant capacity was present.

Conclusion: Serum VCAM-1 increases in RA, and it correlates with disease activity, oxidative stress, and inflammatory markers.

Keywords: VCAM-1, endothelial dysfunction, oxidative stress, rheumatoid arthritis

Saudi Med J 2021; Vol. 42 (6): 620-628

doi: $10.15537 /$ smj.2021.42.6.20200753

From the Medical Physiology Department (Salem), and from Internal Medicine Department (Zahran), Immunology \& Rheumatology Unit, Faculty of Medicine, Menoufia University, Egypt.

Received 3rd January 2021. Accepted 9th April 2021.

Address correspondence and reprint request to: Dr. Heba R. Salem, Medical Physiology Department, Faculty of Medicine, Menoufia University, Menoufia, Egypt.E-mail: heba.salem.12@med.menofia.edu.eg ORCID ID: http://orcid.org/0000-0003-2871-5190 
$\mathrm{R}^{\mathrm{h}}$ heumatoid arthritis (RA) is an immune mediated inflammatory disease of synovial joints, which may be associated with extra-articular features affecting various organs such as the skin, the eyes, the heart and the lungs. ${ }^{1}$ Rheumatoid arthritis patients have a higher mortality rate than healthy subjects, which is mainly attributed to cardiovascular complications. ${ }^{2}$ The high prevalence of traditional cardiovascular risk factors such as hypertension, diabetes mellitus, obesity and sedentary lifestyle contributes to the increased cardiovascular risk in RA patients. Also, nontraditional risk factors such as inflammation, hyperuricemia and renal impairment have a role. The inflammatory environment in RA can lead to structural and functional changes in the arterial wall., ${ }^{3,4}$ Cardiovascular risk in RA patients is mainly due to atherosclerosis, which is an outcome of endothelial dysfunction. ${ }^{5}$ Endothelial dysfunction in RA patients was first reported in 2002 by Bergholm et al. ${ }^{6}$ The pathophysiological mechanisms underlying endothelial dysfunction in RA patients could be attributed to traditional cardiovascular risk factors and inflammation. Also, there is an association between endothelial dysfunction and the high expression of adhesion molecules and inflammatory mediators. ${ }^{7}$ One of the important adhesion molecules that plays a role in endothelial dysfunction is vascular cell adhesion molecule-1 (VCAM-1), which is a glycoprotein expressed by endothelial cells. Vascular cell adhesion molecule-1 mediates leukocytes-endothelial cell adhesion during inflammation. ${ }^{8}$ The soluble VCAM-1 could be considered as a biomarker for the assessment of endothelial dysfunction. ${ }^{9}$ It is also expressed on macrophages, spleen, thymus and Kupffer cells under noninflammatory status. Vascular cell adhesion molecule-1 is involved in pathophysiology of multiple disorders such as autoimmune diseases, cardiovascular diseases and tumor metastasis. ${ }^{10}$ The expression of VCAM-1 is upregulated by proinflammatory cytokines such as tumor necrosis factor- $\alpha$ (TNF- $\alpha$ ), reactive oxygen species, hyperglycemia, shear stress, and toll-like receptor agonists. ${ }^{11}$

Furthermore, previous studies revealed that oxidative stress and inflammation play a role in the pathophysiology of RA patients. ${ }^{12,13}$ Growing evidence suggests that the inflammatory mediators and oxidative

Disclosure. Authors have no conflict of interests, and the work was not supported or funded by any drug company. stress are implicated in the increased cardiovascular burden in RA patients. ${ }^{14}$ Thus, the present study aims to assess serum VCAM-1 as a biomarker of endothelial dysfunction in RA patients and to determine whether there is any correlation between serum VCAM-1 level and oxidative stress markers (serum malondialdehyde [MDA] and total antioxidant capacity), inflammatory markers (erythrocyte sedimentation rate [ESR] and C-reactive protein [CRP]), and Disease Activity Score-28 (DAS28) to evaluate their probability to anticipate endothelial dysfunction and future cardiovascular risk in RA.

Methods. This study was designed as a crosssectional case-control study. One-hundred patients who met the 2010 American College of Rheumatology/ European League against Rheumatism (ACRIEULAR) classification criteria for $\mathrm{RA}^{15}$ were selected from out-patient clinics of rheumatology, Internal Medicine Department, Menoufia University Hospital from May 2019 to May 2020. Fifty patients previously diagnosed with RA for more than 6 months were included as Group I, while 50 patients newly diagnosed with RA was included as Group II. Fifty healthy age- and gender-matched individuals were included as a control group (Group III). The treatment received by treated RA patients in Group I was methotrexate (12.5-25 mg/week), leflunomide (20 mg/day), and hydroxychloroquine ( $400 \mathrm{mg} /$ day).

The exclusion criteria were as follows: age less than 16 years, pregnancy, patients with other autoimmune diseases, acute severe infection, acute cardiovascular event, diabetes mellitus, hypertension, malignancy, smokers, patients on angiotensin-converting enzyme inhibitor, oral contraceptive pills or statins, and patients with diseases that may cause dyslipidemia, namely, hypothyroidism and nephrotic syndrome.

This study followed the ethical standards of our institution and was carried out according to Helsinki Declaration. Informed consent from all patients and controls were obtained per the local ethical committee. The assessment of patients was based on demographics, duration of the disease, clinical symptoms, and physical examination. Disease activity was assessed using DAS28. ${ }^{16}$

Biochemical analysis. Venous blood samples were collected from patients and control subjects after 10-12 hours of overnight fasting under complete aseptic conditions. Complete blood count, random blood glucose, and ESR were determined. The serum was separated within one hour of collection. Lipid profile and rheumatoid factor (RF), CRP, anti-cyclic 
citrullinated peptide (anti-CCP) antibodies, urea, and creatinine were measured for patients and control subjects. The rest of the serum was stored at $-80^{\circ} \mathrm{C}$ until further analysis. The level of serum VCAM-1 was measured by Human VCAM-1 PicoKine ${ }^{\mathrm{TM}}$ ELISA Kit (Boster Biological Technology, USA, Catalog number EK0537) according to the manufacturer's instructions. Total antioxidant capacity and MDA were measured in the serum using colorimetric kits (Biodiagnostic Company, Dokki, Giza, Egypt). The atherogenic index was calculated according to the following formula: Log [triglycrides (TG)/high-density lipoprotein (HDL)]. ${ }^{17}$

Statistical analysis. IBM SPSS Statistics for Windows, version 20 (IBM Corp., Armonk, N.Y., USA) was used for data analysis. The continuous variables were presented as mean \pm standard deviation (SD). Then, one-way ANOVA followed by a post hoc Tukey test was used to compare the results among the 3 groups and a t-test was used to compare the results between the 2 groups. The qualitative variables were expressed in the numeral and percentage forms. Then, they were analyzed by applying the Chi-square and Fisher's exact tests. Correlation between variables was analyzed using the Pearson coefficient. The significance level was set at $\leq 0.05$.

Results. Regarding demographic and clinical characteristics of the studied groups, there were no significant statistical differences in age $(p=0.165)$ or gender $(p=0.801)$ between the studied patients and the control subjects. Also, no significant statistical differences in the number of joints involved $(p=0.252)$, $\operatorname{cardiac}(p=0.558)$, or pulmonary $(p=1)$ affection between
RA patients in groups I and II were observed. Three patients presented with pericardial effusion and one patient with pleural effusion. DAS28 was significantly higher in newly diagnosed patients with RA in Group II than in treated patients in Group I ( $p=0.05)$, (Table 1$)$. Complete blood count (CBC) and random blood glucose analyses revealed a significant statistical difference $(p<0.001)$ in $\mathrm{Hb}$ level between the studied RA patients in groups I and II and the control subjects. Hemoglobin level was significantly lower in RA patients in groups I and II than in the control group $(p<0.001)$. However, there was no significant statistical difference between the studied RA patients in groups I and II $(p=0.247)$. There was no significant statistical difference between the studied groups regarding white blood cells (WBCs) $(p=0.199)$, platelets count $(p=0.408)$, and random blood glucose $(p=0.986)$ (Table 2$)$.

Regarding the inflammatory markers, the studied RA patients showed significantly higher values of ESR and CRP $(p<0.001)$ than control subjects. The newly diagnosed patients in Group II showed significantly higher values than treated patients in Group I $(p<0.001)$ (Table 2).

Regarding lipid profile, there was a significant statistical difference between the studied RA patients and the control subjects. Treated RA patients in Group I showed significantly higher total cholesterol $(p=0.008)$, triglycerides $(p<0.001)$, and atherogenic index $(p=0.011)$ when compared with the corresponding values of the control group. There was no significant statistical difference between treated RA patients in Group I and the control group regarding LDL $(p=0.202)$. Also, newly diagnosed patients in

Table 1 - Demographic and clinical data of the studied groups ( $\mathrm{N}=150)$.

\begin{tabular}{|c|c|c|c|c|c|}
\hline \multirow[t]{2}{*}{ Demographic } & \multicolumn{2}{|c|}{ Rheumatoid arthritis patients } & \multirow{2}{*}{$\begin{array}{c}\text { Group III } \\
\text { (Control) } \\
(\mathbf{n}=50)\end{array}$} & \multirow{2}{*}{$\begin{array}{c}\text { Test of } \\
\text { significance }\end{array}$} & \multirow[t]{2}{*}{$P$-value } \\
\hline & $\begin{array}{c}\text { Group I } \\
(n=50)\end{array}$ & $\begin{array}{c}\text { Group II } \\
(\mathbf{n}=50)\end{array}$ & & & \\
\hline Age (year) $($ mean $\pm S D)$ & $39.7 \pm 7.8$ & $36.0 \pm 10.4$ & $38.5 \pm 6.3$ & 2.6 & 0.165 \\
\hline $\begin{array}{l}\text { Gender }(\%) \\
\text { Male } \\
\text { Female }\end{array}$ & $\begin{array}{l}5(10) \\
45(90)\end{array}$ & $\begin{array}{c}4(8) \\
46(92)\end{array}$ & $\begin{array}{c}6(12) \\
44(88)\end{array}$ & 0.394 & 0.801 \\
\hline No. of joints affected & $11.7 \pm 3.6$ & $11.1 \pm 2.3$ & - & 1.151 & 0.558 \\
\hline Cardiac affection & 2 & 1 & - & 0.5 & 0.3 \\
\hline Pulmonary affection & 1 & 0 & - & 0.001 & 1 \\
\hline GIT affection & 0 & 0 & & - & \\
\hline Renal affection & 0 & 0 & & - & \\
\hline DAS28 & $2.3 \pm 0.75$ & $4.4 \pm 0.1$ & - & 3.6 & 0.05 \\
\hline
\end{tabular}

Data are expressed as mean \pm SD for quantitative data or number percentage for qualitative data unless indicated. DAS-28: Disease Activity Score-28. $p \leq 0.05$ is significant. 
Group II showed significantly higher total cholesterol $(p=0.019)$, triglycerides $(p<0.001)$, LDL $(p=0.015)$, and the atherogenic index $(p=0.001)$ when compared with the corresponding values of the control group. High density lipoprotein was significantly higher in the control subjects than in RA patients in both groups $(p<0.001)$. However, there was no significant statistical difference $(p>0.05)$ between the studied RA patients in groups I and II (Table 2).

Regarding serum VCAM-1, there was a significant statistical difference between the studied RA patients and the control subjects. Serum VCAM-1 was significantly higher in RA patients than in control subjects $(p<0.001)$. Also, it was significantly higher in newly diagnosed patients with RA than in treated patients $(p<0.001)$ (Table 3$)$.

Regarding oxidative stress markers, there were significant statistical differences in total antioxidant capacity $(p=0.05)$ and MDA $(p<0.001)$ between the studied RA patients and the control subjects. Serum MDA was significantly higher in RA patients than in the control subjects $(p<0.001)$. Also, newly diagnosed patients with RA showed significantly higher values than treated patients $(p=0.025)$. Besides, total antioxidant capacity was significantly lower in RA patients than in the control subjects $(p<0.001)$, and it was significantly lower in newly diagnosed patients with RA than in treated patients $(p<0.001)$ (Table 3$)$.

Correlation analysis showed a significant statistical positive correlation between serum VCAM- 1 and DAS28 in patients with $\mathrm{RA}(\mathrm{r}=0.65, p<0.001)$ (Figure 1). Also, there was a significant statistical positive correlation between DAS28 with ESR ( $\mathrm{r}=0.65, p<0.001)$, CRP $(\mathrm{r}=0.55, p<0.001)$, and MDA ( $\mathrm{r}=0.21, p=0.03)$ levels, and a significant statistical negative correlation between DAS28 and total antioxidant capacity $(\mathrm{r}=-0.31$, $p=0.001)$ in patients with RA (Figure 2).

Table 2 - Laboratory data of the studied groups $(\mathrm{N}=150)$.

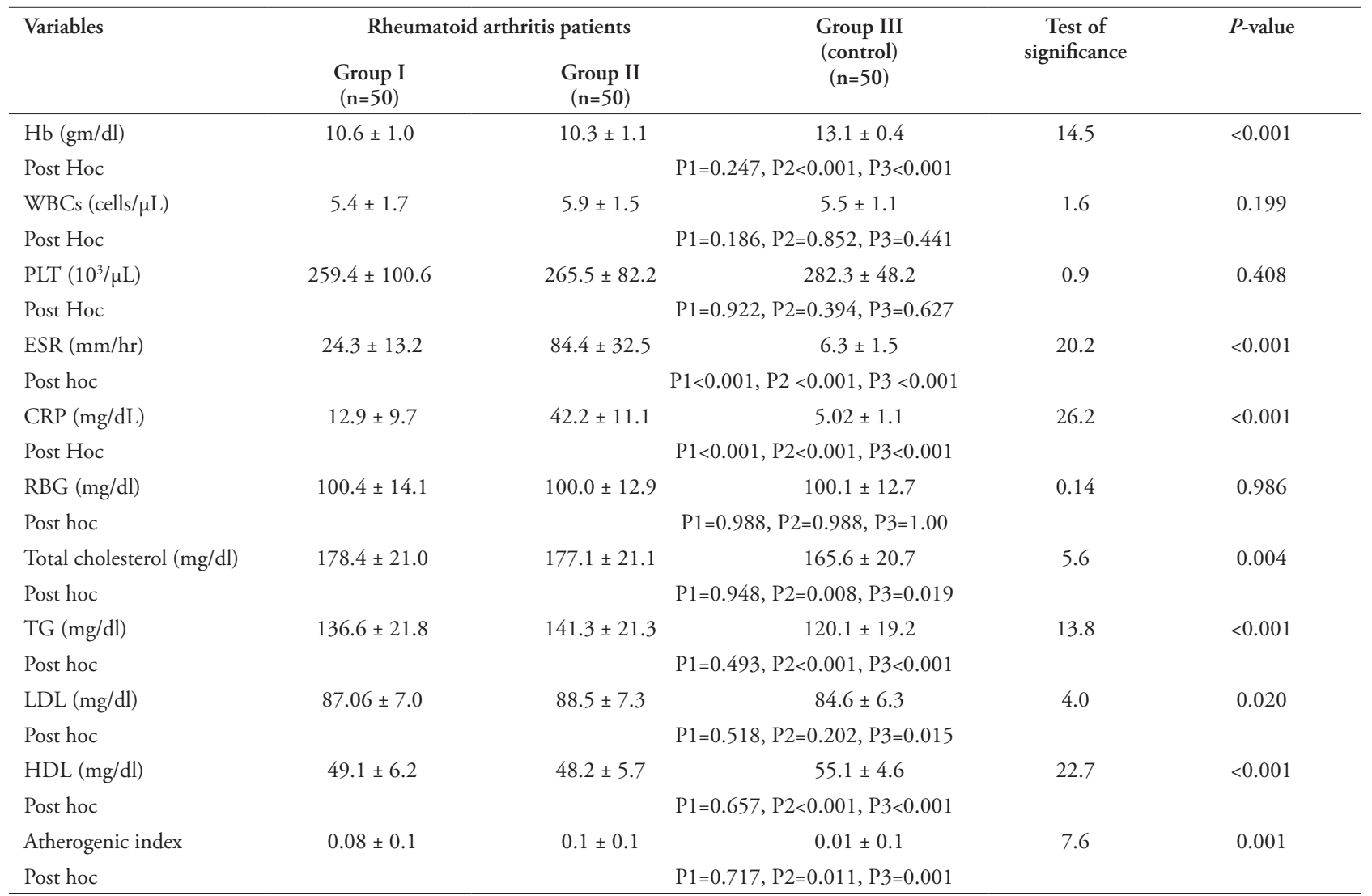

Data are expressed as mean \pm SD. Hb: Hemoglobin, WBCS: white blood cells, PLT: platelets, ESR: erythrocyte sedimentation rate, CRP: C-reactive protein, RBG: random blood glucose. TG: triglycerides, LDL: low density lipoprotein, HDL: high density lipoprotein. P1: Group I vs II, P2: Group I vs III, P3: Group II vs III. $P<0.05$ is significant. $P \leq 0.001$ is highly significant. 


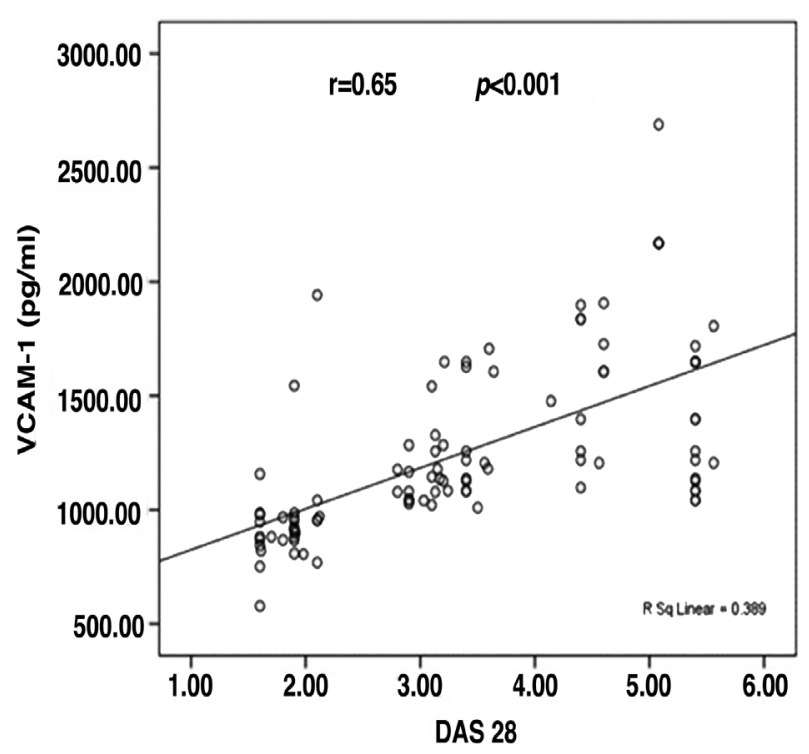

Figure 1 - Scatter plot representing the correlation between Disease Activity Score-28 (DAS28) and serum level of vascular cell adhesion molecule-1 (VCAM-1). $\mathrm{r}=$ correlation coefficient. $P<0.001$ is highly significant.

A
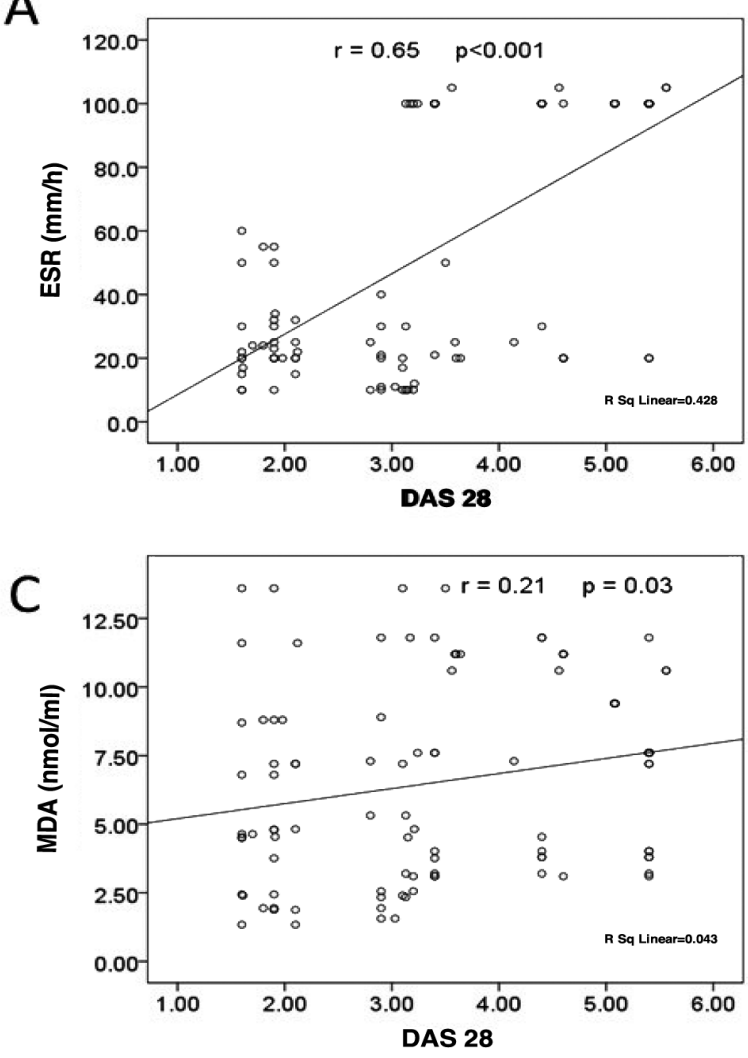

Furthermore, there was a significant statistical positive correlation between serum VCAM-1 with ESR $(\mathrm{r}=0.61, p<0.001)$, CRP $(\mathrm{r}=0.31, p<0.001)$, and MDA $(\mathrm{r}=0.37, p<0.001)$ levels, and a significant statistical negative correlation between serum VCAM-1 and total antioxidant capacity $(\mathrm{r}=-0.39, p<0.001)$ in patients with RA (Figure 3).

Discussion. Patients with RA are prone to cardiovascular morbidity and mortality. ${ }^{18}$ Endothelial dysfunction is the initial step in the development of cardiovascular disease in chronic inflammatory diseases even if atherosclerosis is not present. ${ }^{4}$ Thus, early diagnosis and treatment of endothelial dysfunction in RA could reduce cardiovascular complications. Also, systemic inflammation and oxidative stress have been proven to play a role in the increased cardiovascular risk in RA patients. ${ }^{19}$ Therefore, in this study, we aimed to assess serum VCAM-1 as a biomarker of endothelial dysfunction in RA patients and to correlate it with DAS28, oxidative stress, and inflammatory markers.
B
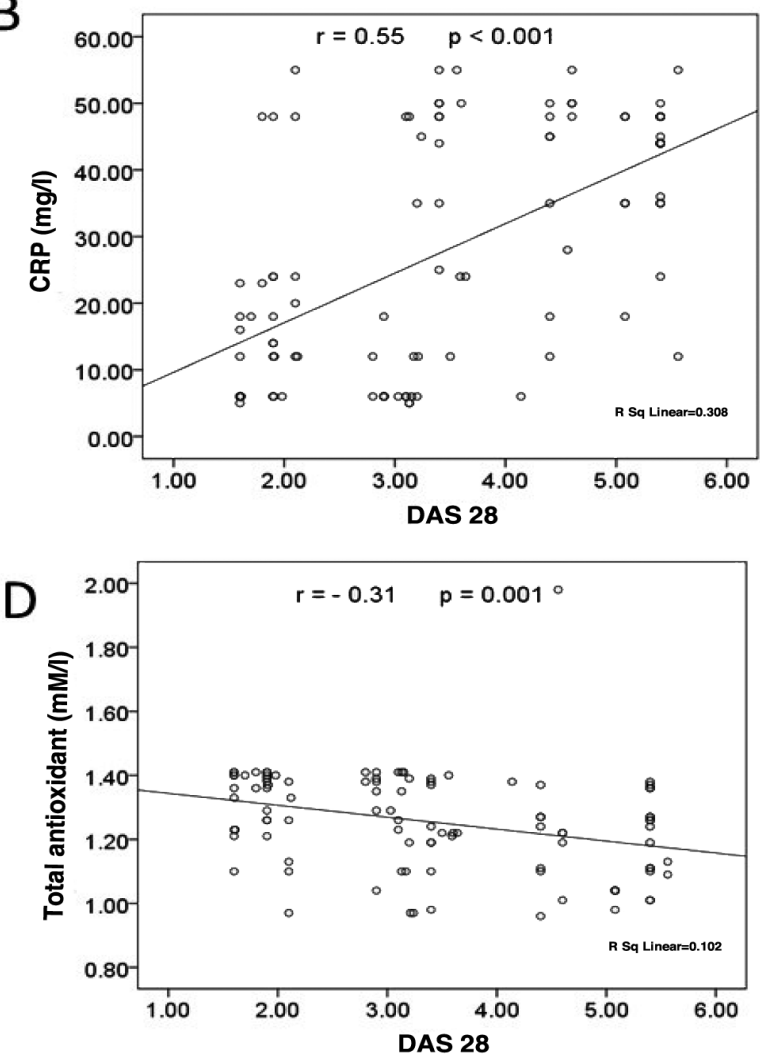

Figure 2 - Scatter plot representing the correlation between Disease Activity Score-28 (DAS28) and A) erythrocyte sedimentation rate (ESR), B) C-reactive protein (CRP), C): malondialdehyde (MDA), and D): total antioxidant capacity. $\mathrm{r}=$ correlation coefficient. $P<0.05$ is significant. $P<0.001$ is highly significant. 
VCAM-1 in rheumatoid arthritis ... Salem \& Zahran

Table 3 - Endothelial dysfunction and oxidative stress markers in the studied groups.

\begin{tabular}{|c|c|c|c|c|c|}
\hline Variables & \multicolumn{2}{|c|}{$\begin{array}{l}\text { Rheumatoid arthritis patients } \\
\qquad \mathrm{N}=100\end{array}$} & $\begin{array}{c}\text { Control } \\
\mathrm{N}=50\end{array}$ & Test of significance & $P$-value \\
\hline VCAM-1 (pg/ml) & \multicolumn{2}{|c|}{$1258.1 \pm 386.3$} & $759.9 \pm 169.2$ & 8.6 & $<0.001$ \\
\hline Total antioxidant capacity (mM/L) & \multicolumn{2}{|c|}{$1.2 \pm 0.1$} & $1.3 \pm 0.1$ & 1.9 & 0.05 \\
\hline \multirow[t]{2}{*}{$\operatorname{MDA}(\mathrm{nmol} / \mathrm{ml})$} & \multicolumn{2}{|c|}{$6.5 \pm 3.5$} & $4.08 \pm 2.5$ & 4.3 & $<0.001$ \\
\hline & $\begin{array}{l}\text { Group } 1 \\
\mathrm{~N}=50\end{array}$ & $\begin{array}{c}\text { Group } 2 \\
\mathrm{~N}=50\end{array}$ & $\begin{array}{c}\text { Control } \\
\mathrm{N}=50\end{array}$ & & \\
\hline VCAM-1 (pg/ml) & $\begin{array}{c}\text { Mean } \pm \text { SD } \\
1022.1 \pm \\
200.1\end{array}$ & $\begin{array}{c}\text { Mean } \pm \text { SD } \\
1494.1 \pm 384.5\end{array}$ & $\begin{array}{c}\text { Mean } \pm \text { SD } \\
759.9 \pm 169.2\end{array}$ & 95.8 & $<0.001$ \\
\hline \multicolumn{6}{|c|}{$\mathrm{P} 1<0.001, \mathrm{P} 2<0.001, \mathrm{P} 3<0.001$} \\
\hline Total antioxidant capacity (mM/L) & $1.3 \pm 0.1$ & $1.1 \pm 0.2$ & $1.3 \pm 0.1$ & 13.0 & $<0.001$ \\
\hline \multicolumn{6}{|c|}{$\mathrm{P} 1<0.001, \mathrm{P} 2=0.832, \mathrm{P} 3<0.001$} \\
\hline $\operatorname{MDA}(\mathrm{nmol} / \mathrm{ml})$ & $5.6 \pm 3.7$ & $7.3 \pm 3.1$ & $4.08 \pm 2.5$ & 13.2 & $<0.001$ \\
\hline \multicolumn{6}{|c|}{$\mathrm{P} 1=0.025, \mathrm{P} 2=0.035, \mathrm{P} 3<0.001$} \\
\hline
\end{tabular}

Data are expressed as mean \pm SD. VCAM-1: vascular cell adhesion molecule-1. MDA: malondialdehyde. P1: Group I vs II, P2: Group I vs III, P3: Group II vs III. $P \leq 0.05$ is significant. $P<0.001$ is highly significant.
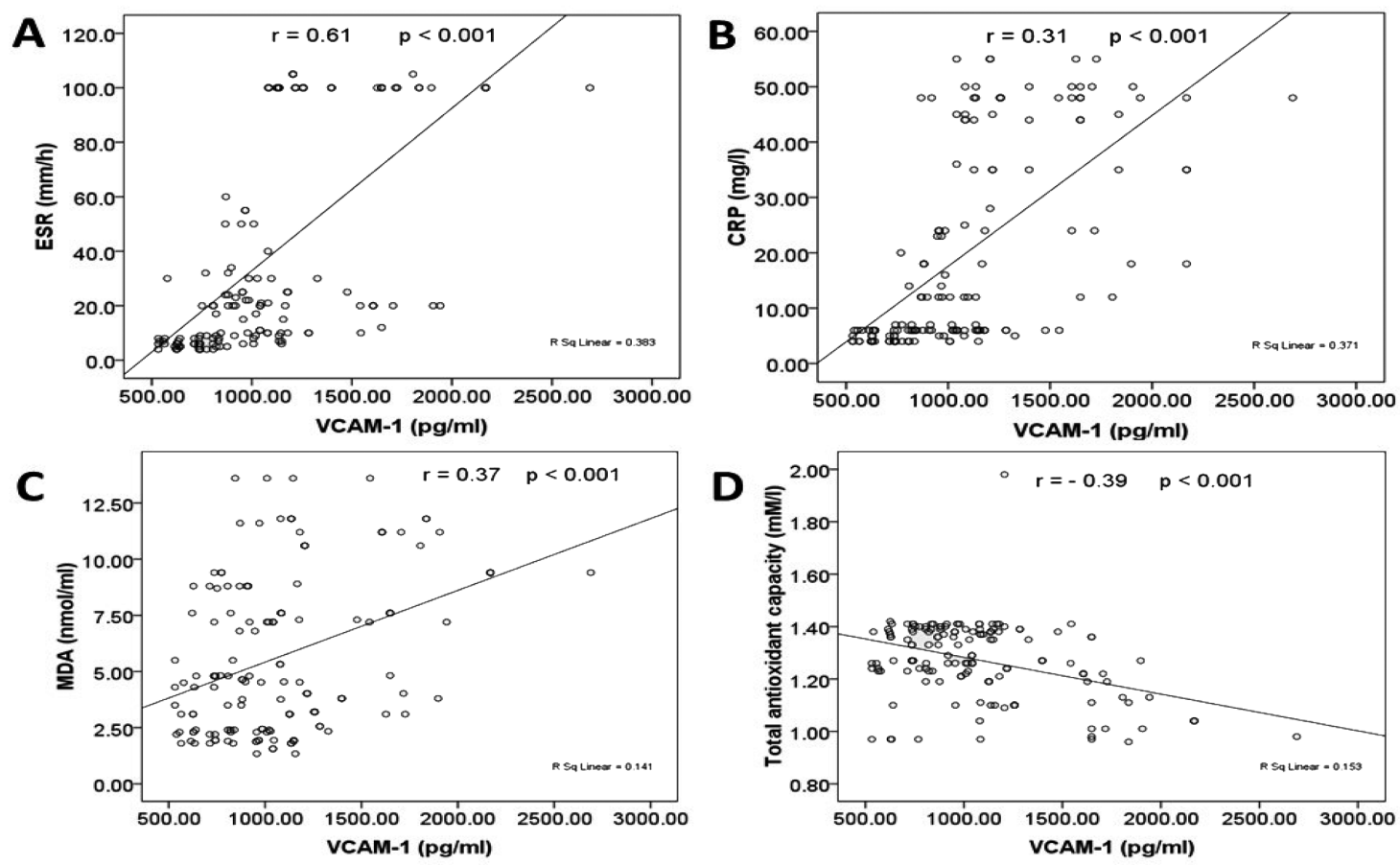

Figure 3 - Scatter plot representing the correlation between serum level of Vascular Cell Adhesion Molecule-1 (VCAM-1) and A) erythrocyte sedimentation rate (ESR), B) C-reactive protein (CRP), C) malondialdehyde (MDA), and D) total antioxidant capacity. $\mathrm{r}=$ correlation coefficient. $P<0.05$ is significant. $P<0.001$ is highly significant.

There is a strong association between VCAM-1 expression with RA. ${ }^{20}$ Our results revealed a significant increase in serum VCAM-1 in the studied RA patients compared with the control group. This confirms the presence of endothelial dysfunction in RA patients. ${ }^{6,7,21}$ Similarly, Södergren et al ${ }^{22}$ reported that serum VCAM-1 levels were significantly higher in patients with RA than in controls. On stimulation by proinflammatory mediators such as tumor necrosis factor- $\alpha$ (TNF- $\alpha)$, IL-1 and IL- 6 , the expression of VCAM-1 on chondrocytes and synovial tissue is upregulated. ${ }^{23}$ The high expression of adhesion molecules by the activated endothelium is a 
key feature of atherosclerosis. Cholesterol accumulation in the arterial wall induces expression of VCAM-1 in the endothelial cells. ${ }^{24}$ The increase of cell adhesion molecules in autoimmune diseases could be explained by the presence of autoantibodies, increased production of proinflammatory cytokines, and oxidative stress. ${ }^{25}$ Vascular cell adhesion molecule 1 affects the inflammatory process, which might be related to the initiation and progression of RA and also its predisposed cardiovascular risk. ${ }^{26}$

In this study, serum VCAM-1 was significantly higher in newly diagnosed rather than treated patients. In a study by Hidayat et $\mathrm{al}^{27}{ }^{27}$ treatment with hydroxychloroquine $(400 \mathrm{mg} /$ day for 12 weeks) was proven to decrease serum VCAM-1 levels, which agrees with our results. Also, in agreement with our results Smith et $\mathrm{al}^{28}$ reported significantly lower VCAM-1 levels in RA patients treated with disease-modifying antirheumatic drugs such as methotrexate. Low et al ${ }^{29}$ reported that RA patients treated with TNF- $\alpha$ inhibitors showed lower incidence and severity of myocardial infarction compared with patients treated with diseasemodifying antirheumatic drugs. Inhibition of TNF- $\alpha$ by adalimumab suppresses VCAM-1 upregulation in the human endothelial cells from umbilical vein that are stimulated by TNF- $\alpha .{ }^{30}$ A national cohort study by Lee et $\mathrm{al}^{31}$ reported that treatment with TNF- $\alpha$ inhibitors was able to reduce the cardiovascular risk in patients with inflammatory arthritis by improving systemic inflammation. These data suggest that good control of disease activity in RA could improve endothelial dysfunction and delay cardiovascular complications.

The significantly lower serum VCAM-1 levels in the treated rather than newly diagnosed patients propose that serum levels of VCAM-1 may be related to the disease activity. Our results revealed a significant statistically positive correlation between serum VCAM-1 and DAS28 in RA patients. Similarly, Davies et $\mathrm{al}^{32}$ concluded that serum VCAM-1 levels correlate with disease activity and cardiovascular risk in RA. These results suggest that serum VCAM 1 level can indicate the disease activity and, to some degree, the effect of treatment. Therefore, control of disease activity leads to reduction of cardiovascular events hence better cardiovascular outcome in RA.

Vascular cell adhesion molecule-1 could be a new therapeutic target in many immunological diseases, including RA. Previous reports have reported that anti-VCAM-1 monoclonal antibody injection into a collagen-induced RA mouse model decreased the severity, but not the incidence of arthritis compared with the control mice. There were fewer arthritic joints in the histological study of the treated mice; however, the arthritic joints showed a similar range of severity compared with the control mice. ${ }^{20}$

There was a significant increase in cholesterol, TG, LDL, and atherogenic index values with lower HDL values in RA patients than in control subjects. However, the values of the lipid profile were within the normal level. Dyslipidemia is a common and predisposed finding in RA patients owing to endothelial dysfunction and cardiovascular diseases. ${ }^{33,34}$ In this study, there was endothelial dysfunction even with the normal lipid profile in the selected RA patients. Therefore, a search for other nontraditional risk factors should be investigated.

The role of oxidative stress in the pathophysiology of inflammatory diseases, such as RA, has been established in numerous studies. ${ }^{35}$ In this study, patients with RA showed oxidative stress, as evidenced by a significant increase of serum MDA, a lipid peroxidation product, in RA patients than in controls. This agrees with a previous study by Das et al. ${ }^{36}$ Malondialdehyde can combine with acetaldehyde (AA) to form malondialdehydeacetaldehyde (MAA), which in turn can modify proteins producing an MAA protein adduct. It has been suggested that MAA protein adducts and anti-MAA immune reactions could have a role in RA pathogenesis. ${ }^{37}$ Also, total antioxidant capacity was significantly lower in the studied RA patients than in controls. These results agree with previous studies by Zhou et $\mathrm{al}^{38}$ and Mititelu et al. ${ }^{39}$ Serum MDA were significantly higher, and total antioxidant capacity was significantly lower in newly diagnosed than in treated patients. Oxidative stress enhances endothelial dysfunction, which is the leading cause of cardiovascular complications. ${ }^{40}$

There is a back-and-forth relationship between inflammation and oxidative stress. Both are the main triggers for cardiovascular diseases. ${ }^{41}$ In this study, systemic inflammation was assessed by ESR and CRP. They were significantly higher in newly diagnosed patients than in treated patients. The causal relationship between systemic inflammation and endothelial dysfunction suggests that CRP and ESR could be used as predictors of endothelial dysfunction. ${ }^{42}$

Furthermore, there was a significant positive correlation between serum MDA level and DAS28 and a significant negative correlation between total antioxidant capacity and DAS28 in patients with RA. A 2016 meta-analysis investigated whether oxidative biomarkers could be used as adjuvants in tracking disease progression. It found a positive correlation between the serum levels of MDA and disease activity, reinforcing the supposition that oxidative stress and 
disease activity in RA move toward a similar direction. Previous studies showed that there is a positive correlation between serum MDA level and DAS28 and a negative correlation between total antioxidant capacity and DAS $28,38,43$ These results suggest that serum MDA levels and total antioxidant capacity can reflect the disease activity and, to some extent, the efficacy of treatment. Moreover, ESR and CRP have a relationship with DAS28, which agrees with our results. ${ }^{44}$

In this study, we investigated the correlation between endothelial dysfunction assessed by serum VCAM-1 with serum MDA, total antioxidant capacity, CRP, and ESR in RA patients. Our results revealed a significant positive correlation between serum VCAM-1 with serum MDA, CRP, and ESR. Also, a significant negative correlation between serum VCAM-1 with total antioxidant capacity was present. In line with our results, Serkova et $\mathrm{al}^{45}$ found a correlation between VCAM-1 and CRP in patients with coronary heart disease. Also, hydrogen peroxide was reported to enhance the expression of VCAM-1 in cultured endothelial cells from human umbilical vein, supporting the relationship between VCAM- 1 and oxidative stress; ${ }^{46}$ oxidative stress markers (serum MDA and total antioxidant capacity) and inflammatory markers (CRP and ESR) could predict endothelial dysfunction and further cardiovascular risk in RA.

Study limitations. The limitations to this study were the small sample size, that other markers of endothelial dysfunction were not assessed, and that the gene polymorphisms of VCAM-1 that might affect the endothelial dysfunction in these patients were not studied. Further studies should be carried out on a large number of RA patients.

In conclusion, serum VCAM-1, a marker of endothelial dysfunction, increases in RA and correlates with disease activity. Markers of oxidative stress (serum MDA and total antioxidant capacity) and inflammatory markers (ESR and CRP) correlate with serum VCAM-1 and disease activity. Thus, ESR and CRP could be alternative predictors of endothelial dysfunction in RA patients because they are cheaper and easier to measure than VCAM-1. Further studies on a larger number of patients with a longer duration of treatment are now required.

Acknowledgment. We would like to thank American Manuscript Editors (https://www.americanmanuscripteditors.com) for English language editing.

\section{References}

1. Das S, Padhan P. An overview of the extraarticular involvement in rheumatoid arthritis and its management. J Pharmacol Pharmacother 2017; 8: 81.

2. Lee KS, Kronbichler A, Eisenhut M, Lee KH, Shin JI. Cardiovascular involvement in systemic rheumatic diseases: an integrated view for the treating physicians. Autoimmun Rev 2018; 17: 201-214.

3. Hannawi S, Hannawi H, Al Salmi I. Cardiovascular disease and subclinical atherosclerosis in rheumatoid arthritis. Hypertension Research 2020; 43: 982-984.

4. Reiss AB, Silverman A, Khalfan M, Vernice NA, Kasselman LJ, Carsons SE, et al. Accelerated atherosclerosis in rheumatoid arthritis: Mechanisms and treatment. Curr Pharm Des 2019; 25: 969-986.

5. Mahmoudi M, Aslani S, Fadaei R, Jamshidi AR. New insights to the mechanisms underlying atherosclerosis in rheumatoid arthritis. Int J Rheum Dis 2017; 20: 287-297.

6. Bergholm R, Leirisalo-Repo M, Vehkavaara S, Mäkimattila $\mathrm{S}$, Taskinen M-R, Yki-Järvinen H. Impaired responsiveness to $\mathrm{NO}$ in newly diagnosed patients with rheumatoid arthritis. Arterioscler Thromb Vasc Biol 2002; 22: 1637-1641.

7. Totoson P, Maguin-Gaté K, Nappey M, Wendling D, Demougeot C. Endothelial dysfunction in rheumatoid arthritis: mechanistic insights and correlation with circulating markers of systemic inflammation. PloS One 2016; 11: e0146744.

8. Edlinger C, Lichtenauer M, Wernly B, Pistulli R, Paar V, Prodinger C, et al. Disease-specific characteristics of vascular cell adhesion molecule- 1 levels in patients with peripheral artery disease. Heart Vessels 2019; 34: 976-983.

9. Lopez-Vilchez I, Diaz-Ricart M, Navarro V, Torramade S, Zamorano-Leon J, Lopez-Farre A, et al. Endothelial damage in major depression patients is modulated by SSRI treatment, as demonstrated by circulating biomarkers and an in vitro cell model. Transl Psychiatry 2016; 6: e886.

10. Schlesinger M, Bendas G. Vascular cell adhesion molecule-1 (VCAM-1)-An increasing insight into its role in tumorigenicity and metastasis. Int J Cancer 2015; 136: 2504-2514.

11. Cook-Mills JM, Marchese ME, Abdala-Valencia H. Vascular cell adhesion molecule-1 expression and signaling during disease: regulation by reactive oxygen species and antioxidants. Antioxid Redox Signal 2011; 15: 1607-1638.

12. Alunno A, Carubbi F, Giacomelli R, Gerli R. Cytokines in the pathogenesis of rheumatoid arthritis: new players and therapeutic targets. BMC Rheumatol 2017; 1: 1-13.

13. Quiñonez-Flores CM, González-Chávez SA, Del Río Nájera D, Pacheco-Tena C. Oxidative stress relevance in the pathogenesis of the rheumatoid arthritis: a systematic review. Biomed Res Int 2016; 2016: 6097417.

14. Castañeda S, Nurmohamed MT, González-Gay MA. Cardiovascular disease in inflammatory rheumatic diseases. Best Pract Res Clin Rheumatol 2016; 30: 851-869.

15. Aletaha D, Neogi T, Silman AJ, Funovits J, Felson DT, Bingham Iii CO, et al. 2010 rheumatoid arthritis classification criteria: an American College of Rheumatology/European League Against Rheumatism collaborative initiative. Arthritis Rheum 2010; 62: 2569-2581.

16. McWilliams DF, Kiely PD, Young A, Joharatnam N, Wilson D, Walsh DA. Interpretation of DAS28 and its components in the assessment of inflammatory and non-inflammatory aspects of rheumatoid arthritis. BMC Rheumatol 2018; 2: 1-12. 
17. Dobiás-ová M, Frohlich J. The plasma parameter log (TG/ HDL-C) as an atherogenic index: correlation with lipoprotein particle size and esterification rate inapob-lipoprotein-depleted plasma (FERHDL). Clin Biochem 2001; 34: 583-588.

18. Boo S, Oh H, Froelicher ES, Suh C-H. Knowledge and perception of cardiovascular disease risk among patients with rheumatoid arthritis. PloS One 2017; 12: e0176291.

19. England BR, Thiele GM, Anderson DR, Mikuls TR. Increased cardiovascular risk in rheumatoid arthritis: mechanisms and implications. BMJ 2018; 361: k1036.

20. Kong D-H, Kim YK, Kim MR, Jang JH, Lee S. Emerging roles of vascular cell adhesion molecule-1 (VCAM-1) in immunological disorders and cancer. Int J Mol Sci 2018; 19: 1057.

21. Anyfanti P, Triantafyllou A, Gkaliagkousi E, Triantafyllou G, Koletsos N, Chatzimichailidou S, et al. Subendocardial viability ratio in patients with rheumatoid arthritis: comparison with healthy controls and identification of prognostic factors. Clin Rheumatol 2017; 36: 1229-1236.

22. Södergren A, Karp K, Bengtsson C, Möller B, RantapääDahlqvist S, Wållberg-Jonsson S. Biomarkers associated with cardiovascular disease in patients with early rheumatoid arthritis. PloS One 2019; 14: e0220531.

23. Denys A, Clavel G, Lemeiter D, Schischmanoff O, Boissier M-C, Semerano L. Aortic VCAM-1: an early marker of vascular inflammation in collagen-induced arthritis. J Cell Mol Med 2016; 20: 855-863.

24. Galkina E, Ley K. Vascular adhesion molecules in atherosclerosis. Arterioscler Thromb Vasc Biol 2007; 27: 2292-301.

25. Steyers CM, Miller FJ. Endothelial dysfunction in chronic inflammatory diseases. Int J Mol Sci 2014; 15: 11324-1149.

26. Denys A, Clavel G, Lemeiter D, Schischmanoff O, Boissier MC, Semerano L. Aortic VCAM-1: an early marker of vascular inflammation in collagen induced arthritis. J Cell Mol Med 2016; 20: 855-863.

27. Hidayat R, Isbagio H, Alwi I, Soewondo P, Setiabudy R, Jusman SW, et al. The effect of hydroxychloroquine on endothelial dysfunction in patients with rheumatoid arthritis: A doubleblind randomized clinical trial. Int J Clin Rheumtol 2019; 14: 59.

28. Smith M, Slavotinek J, Au V, Weedon H, Parker A, Coleman $M$, et al. Successful treatment of rheumatoid arthritis is associated with a reduction in synovial membrane cytokines and cell adhesion molecule expression. Rheumatology 2001; 40: 965-977.

29. Low AS, Symmons DP, Lunt M, Mercer LK, Gale CP, Watson KD, et al. Relationship between exposure to tumour necrosis factor inhibitor therapy and incidence and severity of myocardial infarction in patients with rheumatoid arthritis. Ann Rheum Dis 2017; 76: 654-660.

30. Oberoi R, Schuett J, Schuett H, Koch A-K, Luchtefeld M, Grote $\mathrm{K}$, et al. Targeting tumor necrosis factor- $\alpha$ with adalimumab: effects on endothelial activation and monocyte adhesion. PLoS One 2016; 11: e0160145.

31. Lee JL, Sinnathurai P, Buchbinder R, Hill C, Lassere M, March L. Biologics and cardiovascular events in inflammatory arthritis: a prospective national cohort study. Arthritis Res Ther 2018; 20: $1-9$.

32. Davies R, Iacono D, Jordan L, Williams J, Rawlings C, Lang $\mathrm{D}$, et al. Serum vascular cell adhesion molecule-1 (VCAM-1) levels are associated with vascular dysfunction and increased cardiovascular risk in an animal model and patients with rheumatoid arthritis: Abstract Number: 1575. Arthritis o Rheumatology 2015; 67: 1965-1967.
33. Batún JG, Olan F, Hernández ÉN. Dyslipidemia and atherogenic risk in patients with rheumatoid arthritis. Clin Investig Arterioscler 2016; 28: 123-131.

34. Dhonthula R, Ram T. Study of Dyslipidemia and Cardio vascular risk in rheumatoid arthritis patients. Indian J Public Health Res Dev 2019; 10: 160-163.

35. Fonseca LJSd, Nunes-Souza V, Goulart MOF, Rabelo LA. Oxidative stress in rheumatoid arthritis: What the future might hold regarding novel biomarkers and add-on therapies. Oxid Med Cell Longev 2019; 2019: 7536805.

36. Das DC, Jahan I, Uddin MG, Hossain MM, Chowdhury MAZ, Fardous Z, et al. Serum CRP, MDA, Vitamin C, and trace elements in Bangladeshi patients with rheumatoid arthritis. Biol Trace Elem Res 2021; 199: 76-84.

37. England BR, Duryee MJ, Roul P, Mahajan TD, Singh N, Poole JA, et al. Malondialdehyde-Acetaldehyde Adducts and Antibody Responses in Rheumatoid Arthritis-Associated Interstitial Lung Disease. Arthritis Rheumatol 2019; 71: 1483-1493.

38. Zhou L, Feng J-T, Zhang L, Kuang Y. Clinical significance of serum total oxidant/antioxidant status for the disease activity in active rheumatoid arthritis. Int J Clin Exp Pathol. 2017;10(8):8895.

39. Mititelu RR, Pădureanu R, Băcănoiu M, Pădureanu V, Docea $\mathrm{AO}$, Calina D, et al. Inflammatory and oxidative stress markersmirror tools in rheumatoid arthritis. Biomedicines 2020; 8: 125.

40. Steven S, Frenis K, Oelze M, Kalinovic S, Kuntic M, Bayo Jimenez MT, et al. Vascular inflammation and oxidative stress: major triggers for cardiovascular disease. Oxid Med Cell Longev 2019; 23; 2019.

41. Steven S, Frenis K, Oelze M, Kalinovic S, Kuntic M, Bayo Jimenez MT, et al. Vascular inflammation and oxidative stress: Major triggers for cardiovascular disease. Oxid Med Cell Longev 2019; 2019: 7092151.

42. Bordy R, Totoson P, Prati Cm, Marie C, Wendling D, Demougeot Cl. Microvascular endothelial dysfunction in rheumatoid arthritis. Nat Rev Rheumatol 2018; 14: 404-420.

43. Grönwall C, Amara K, Hardt U, Krishnamurthy A, Steen J, Engström M, et al. Autoreactivity to malondialdehydemodifications in rheumatoid arthritis is linked to disease activity and synovial pathogenesis. J Autoimmun 2017; 84: 29-45.

44. Orr CK, Najm A, Young F, McGarry T, Biniecka M, Fearon U, et al. The utility and limitations of CRP, ESR and DAS28-CRP in appraising disease activity in rheumatoid arthritis. Front Med 2018; 5: 185.

45. Serkova VK, Pavlov SV, Romanava VA, Monastyrskiy YI, Ziepko SM, Kuzminova NV, et al. Medical expert system for assessment of coronary heart disease destabilization based on the analysis of the level of soluble vascular adhesion molecules. (Proceedings). Wilga (PL): Photonics Applications in Astronomy, Communications, Industry, and High Energy Physics Experiments; 2017.

46. Habas K, Shang L. Alterations in intercellular adhesion molecule 1 (ICAM-1) and vascular cell adhesion molecule 1 (VCAM-1) in human endothelial cells. Tissue Cell 2018; 54: 139-143. 